\title{
Prevalence and Risk Factors of Dyspnea among General Population of Arar City, Kingdom Saudi Arabia
}

\author{
Abdulelah Aziz Eissa Alenzi ${ }^{1}$, Osama Alsallum Alanazi ${ }^{1}$, Tariq Hulayyil Alanazi ${ }^{1}$, Abdulwahab \\ Mabkhoot Ali Meqbel ${ }^{2}$, Nasser Theeb Alqahtani ${ }^{3}$, Munirah Abdullah Almakhayitah ${ }^{4}$, Wejdan jumyaan \\ alharbi ${ }^{5}$, Israa Abed Alfadhli ${ }^{5}$, Wijdan Salem Almatrafi ${ }^{5}$, Asma Salem Almatrafi ${ }^{5}$ \\ 1Faculty of Medicine, Northern Border University, 2Faculty of medicine, King Khalid University, \\ 3Faculty of Medicine, King Saud University, 4 Faculty of Medicine, King Faisal University, \\ 5 Faculty of Medicine Umm-Alqura University
}

\begin{abstract}
Background: Dyspnea is defined as the subjective experience of breathing discomfort. It is increasing by age and it is a common problem affecting up to half of patients admitted to acute, tertiary care hospitals and also affecting one quarter of ambulatory patients.Study objective: to determine the prevalence and risk factors of dyspnea among general population of Arar city, Northern Border Province, Saudi Arabia. Methods: This was a cross-sectional, community-based study. It was conducted on the general population of Arar city during the period from $1^{\text {st }}$ October, 2015 to $30^{\text {th }}$ June 2016.Data were collected using a predesigned online selfadministered questionnaire covering all the needed items. Results: Dyspnea was reported in $35.2 \%$ of the study population. Causes of dyspnea reported in our study were mainly of unknown causes (38.6\%), bronchial asthma (23.9\%), allergy (22.7\%), psychological causes $(12.5 \%)$, cardiac causes $(1.1 \%)$, and COPD (1.1\%).It was more common among females as $44.8 \%$ of females reported dyspnea while it was reported in only $31.7 \%$ of males. Our study has also shown that dyspnea was most prevalent among the $<20$ age group by ratio as $52.6 \%$ of them reported dyspnea. However, $36.1 \%$ of subjects aged between 20 and 40 have reported dyspnea. Precipitating causes of dyspnea were found to be mostly due to dust (30.7\%), smoking (22.7\%), climate changes (14.7\%), nervousness (13.6\%), specific food/ingested material (11.4\%), and excess physical activities (6.8\%). It was also founded in our study that $56.5 \%$ of participants with family history of dyspnea suffered from dyspnea. While $72.9 \%$ of those who did not have a family history of dyspnea did not suffer any dyspnea. Conclusion: Dyspnea was reported in $35.2 \%$ of Arar population. Our study showed that dyspnea was more common among females than males. large scale study with detailed investigations about causes and precipitating factors are required.
\end{abstract}

Keywords: Dyspnea, hard breathing, Prevalence, chronic disease.

\section{INTRODUCTION}

Chronic respiratory diseases represent a group of diseases characterized by abnormal condition of the respiratory system such as inflammation of the airways, airflow obstruction, chest pain, dyspnea, hemoptysis, and sputum production ${ }^{[1]}$. It became a predominant cause of morbidity and mortality, especially in the resource-poor countries such as South and Southeast Asia and Africa ${ }^{[2]}$.

Dyspnea is a normal symptom of heavy exertion but becomes pathological if it occurs in unexpected situations $^{[3]}$ or light exertion. In $85 \%$ of cases it was due to asthma, pneumonia, cardiac ischemia, interstitial lung disease, congestive heart failure, chronic obstructive pulmonary disease, or psychogenic causes $^{[4]}$ such as panic disorder and anxiety. Dyspnea is known as a subjective experience of breathing discomfort that consists of qualitatively distinct sensations that vary in intensity" or as the experience of breathlessness which may be either acute or chronic $^{[3]}$. There are many causes of dyspnea, it may occur in normal condition such as, exercise is usually a trigger for short-term dyspnea or when you at a higher elevation and you're not used to having less oxygen available, you may also experience temporary dyspnea. At extremely high elevations, such as mountaintops, the air can be a real health hazard ${ }^{[4]}$. Also dyspnea may occur due to medical condition and it appear in a sudden breathlessness, as in heart failure, low blood pressure, pneumonia, pulmonary embolism, carbon monoxide poisoning, stress or anxiety or may also experience sudden dyspnea if a piece of food or some other object blocks your airway ${ }^{[5]}$.

An injury that harms a lung or causes a rapid loss of blood will also make breathing more difficult, and all this cases are considered as acute dyspnea but when shortness of breath isn't a sudden emergency, but is instead a problem that lingers for at least four weeks, it's considered chronic cases as in chronic obstructive pulmonary disease (COPD), interstitial lung disease (scarring of lung tissue), poor physical conditioning, obesity, heart disease ${ }^{[6]}$.

The symptoms of chronic dyspnea appear in sensation of just not getting quite enough air into lungs all the time. In serious cases, you may feel as though you're suffocating. Bouts of dyspnea may also 
bring on chest tightness. Dyspnea prevalence has varied greatly across studies and countries ${ }^{[7]}$. Some might be due to differences in the distribution of known correlates of dyspnea such as age, sex, and smoking status ${ }^{[8]}$. Or may differ due to variation in how dyspnea was measured, the nature of the samples studied and the burden of chronic diseases that cause dyspnea. Some population-based studies have reported a dyspnea prevalence of more than $20 \%{ }^{[9]}$. A high-prevalence of cardiopulmonary diseases, lifestyle changes, obesity and subclinical medical conditions might have explained this dyspnea

\section{Objectives}

The aim of this study was to determine the prevalence and risk factors of dyspnea among general population of Arar city, Northern Border Province, Saudi Arabia.

\section{METHODOLOGY}

Study design and setting: This present study is a cross-sectional, community-based study. It was conducted on the general population of Arar city (Northern Border Province, Saudi Arabia) of both sexes, during the period from 1st October, 2015 to 30th June 2016 to evaluate the prevalence of dyspnea among the population of Arar city.

Sampling technique: systematic random technique was followed as we choose the participants randomly from the general population. We include every $20^{\text {th }}$.

\section{Data collection:}

Data were collected using a pre-designed online questionnaire which was distributed among the population. It was self-administered by participants after a brief introduction or explanation of the idea of the research. The questionnaire included the relevant questions to collect the needed data. Collected data included:

1- Socio-demographic characteristics, smoking, obesity, performing muscular exercise, family history of dyspnea.

2- Dyspnea, causes,physician diagnosis and precipitating factors of dyspnea among the studied population.

\section{Statistical analysis}

Collected data were coded and analyzed using statistical package for the social sciences (SPSS, version 15). Descriptive statistics for the prevalence and quantitative variables was used. Relationship between dyspnea and socio-demographic characteristics, smoking, obesity, performing muscular exercise, family history of repeated dyspnea of the studied population was determined using the chi-square test. P-value of less than 0.05 was considered statistically significant.

\section{Ethical considerations:}

The participants were informed that participating is completely voluntary. All the participants were assured that their data will be dealt with confidentiality. No names were written in the forms and the data was kept safely.

\section{RESULTS}

Table (1) shows socio-demographic characteristics, smoking, obesity, performing muscular exercise, family history of repeated dyspnea of the studied population. We found that most of the studied population were males $(73.2 \%), 67.6 \%$ aged from 20 to 40 years and $50.4 \%$ were singles. About education, $80.0 \%$ of population reach university level or more, and $57.6 \%$ were working, $66.0 \%$ not smokers . Regarding obesity, $74.0 \%$ were non obese and $76.4 \%$ do muscular exercise . Family has not a history of dyspnea was present in $28.6 \%$ of the studied sample.

Table (2) discuses repeated dyspnea, causes, physician diagnosis, precipitating causes of dyspnea among the studied sample. We found that, dyspnea was reported in $35.2 \%$ of the studied population sample . Causes of dyspnea were mainly of unknown causes (38.6\%), bronchial asthma (23.9\%), allergy (22.7\%), psychological causes (12.5\%), cardiac causes (1.1\%), and COPD (1.1\%) was more common among females as $44.8 \%$ of females reported dyspnea while it was reported in only $31.7 \%$ of males. Precipitating causes of dyspnea were found to be mostly due to dust $(30.7 \%)$, smoking $(22.7 \%)$, climate changes (14.7\%), nervousness (13.6\%), specific food/ingested material (11.4\%), and excess physical activities (6.8\%).

Our study showed that dyspnea was more common among females as $44.8 \%$ of females reported dyspnea while it was reported in only $31.7 \%$ of males. Our study has also shown that dyspnea was most prevalent among the $<20$ age group by ratio as $52.6 \%$ of them reported dyspnea. However, $36.1 \%$ of subjects aged between 20 and 40 have reported dyspnea. It is also observed in our study that $56.5 \%$ of participants with family history of dyspnea suffered from dyspnea. While $72.9 \%$ of those who did not have a family history of dyspnea did not suffer any dyspnea.

(Table 3) 
Table (1): Socio-demographic characteristics, smoking, obesity, performing muscular exercise, family history of dyspneaamong the studied population

\begin{tabular}{|c|c|c|}
\hline Dyspnea $(n=250)$ & Frequency & Percent \\
\hline - $\quad$ No & 162 & 64.8 \\
\hline - $\quad$ Yes & 88 & 35.2 \\
\hline \multicolumn{3}{|c|}{ Physician diagnosis $(n=250)$} \\
\hline - $\mathrm{No}$ & 197 & 78.8 \\
\hline - Yes & 53 & 21.2 \\
\hline \multicolumn{3}{|l|}{ Causes of dyspnea $(n=88)$} \\
\hline - Psychological causes & 11 & 12.5 \\
\hline - Bronchial asthma & 21 & 23.9 \\
\hline - $\quad$ Allergy & 20 & 22.7 \\
\hline - COPD & 1 & 1.1 \\
\hline - $\quad$ Cardiac causes & 1 & 1.1 \\
\hline - Unknown causes & 34 & 38.6 \\
\hline \multicolumn{3}{|c|}{ Precipitating factors of dyspnea $(n=88)$} \\
\hline - Dust & 27 & 30.7 \\
\hline - $\quad$ Some foods & 10 & 11.4 \\
\hline - $\quad$ Smoking & 20 & 22.7 \\
\hline - Excess physical activities & 6 & 6.8 \\
\hline - Climatic changes & 13 & 14.7 \\
\hline - $\quad$ Nervousness & 12 & 13.6 \\
\hline
\end{tabular}

Table(3): $\quad$ Relationship between dyspnea socio-demographic characteristics, smoking, obesity, performing muscular exercise, family history of dyspnea of the studied population

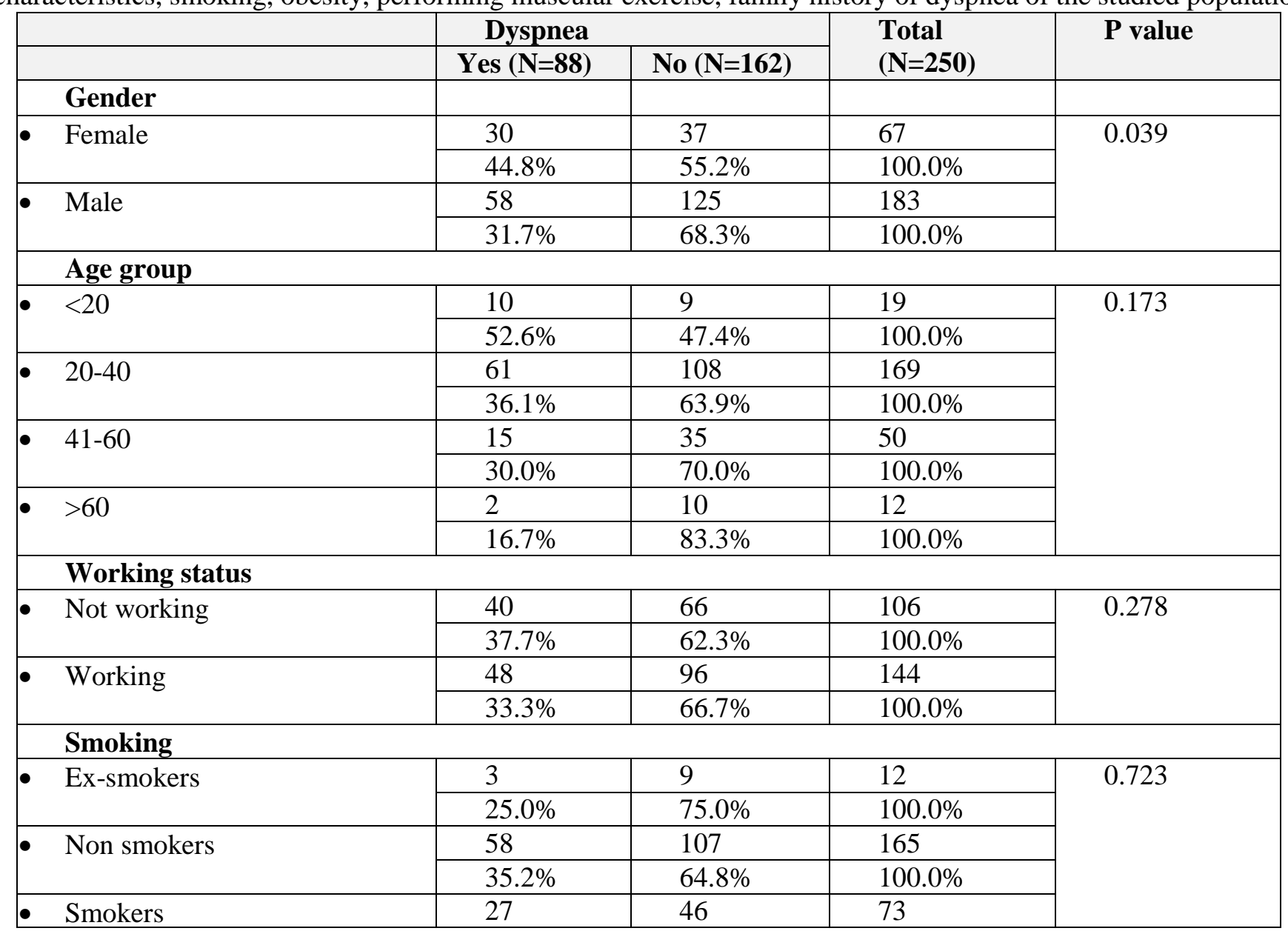




\begin{tabular}{|c|c|c|c|c|}
\hline & \multicolumn{2}{|l|}{ Dyspnea } & \multirow{2}{*}{$\begin{array}{l}\text { Total } \\
(\mathrm{N}=250)\end{array}$} & \multirow[t]{3}{*}{$P$ value } \\
\hline & Yes $(\mathrm{N}=88)$ & No $(\mathrm{N}=162)$ & & \\
\hline & $37.0 \%$ & $63.0 \%$ & $100.0 \%$ & \\
\hline \multicolumn{5}{|c|}{ Obesity } \\
\hline \multirow[t]{2}{*}{ No } & 63 & 122 & 185 & \multirow[t]{4}{*}{0.311} \\
\hline & $34.1 \%$ & $65.9 \%$ & $100.0 \%$ & \\
\hline \multirow{2}{*}{ Yes } & 25 & 40 & 65 & \\
\hline & $38.5 \%$ & $61.5 \%$ & $100.0 \%$ & \\
\hline \multicolumn{5}{|c|}{ Muscular exercises } \\
\hline \multirow[t]{2}{*}{ No } & 64 & 127 & 191 & \multirow[t]{4}{*}{0.197} \\
\hline & $33.5 \%$ & $66.5 \%$ & $100.0 \%$ & \\
\hline \multirow[t]{2}{*}{ Yes } & 24 & 35 & 59 & \\
\hline & $40.7 \%$ & $59.3 \%$ & $100.0 \%$ & \\
\hline \multicolumn{5}{|c|}{ Family history of dyspnea } \\
\hline \multirow[t]{2}{*}{ No } & 49 & 132 & 181 & \multirow[t]{4}{*}{0.001} \\
\hline & $27.1 \%$ & $72.9 \%$ & $100.0 \%$ & \\
\hline \multirow[t]{2}{*}{ Yes } & 39 & 30 & 69 & \\
\hline & $56.5 \%$ & $43.5 \%$ & $100.0 \%$ & \\
\hline
\end{tabular}

\section{DISCUSSION}

Dyspnea is defined as the subjective experience of breathing discomfort ${ }^{[10]}$. It is increasing by age and it is a common problem affecting up to half of patients admitted to acute, tertiary care hospitals ${ }^{[11]}$ and also affecting one quarter of ambulatory patients [12] Mostly, patients' explaining the experience of severe dyspnea are illuminating, and they report association with a sense of impending death [13]. Dyspnea is experienced when there is difficulty in the oxygen transport, with metabolic dysfunction such as in lactic acidosis, high pulmonary vascular pressures as in congestive heart failure, and increased work of breathing as in increased airway resistance and hyperinflation from asthma and chronic obstructive pulmonary disease (COPD) ${ }^{[14]}$. Although COPD is a treatable condition, it remains the third leading cause of death worldwide ${ }^{[15]}$. Reduced oxygen transport can be due to heart failure, emphysema, pulmonary embolism, and anemia. Medical professionals refer to the case with the term dyspnea, while most patients rather describe it with terms such as breathlessness, chest tightness, shortness of breath, and air hunger or as increased effort of breathing which indicates that dyspnea is complex and varies between patients ${ }^{[16]}$. In the study of Sajadiet $\boldsymbol{a l} .{ }^{[17]}$, it was found that "My breath doesn't go out all the way" with $83.1 \%$, "My chest feels tight " with $45.8 \%$, and "I feel that my airway is obstructed" with $40.7 \%$, were the most frequent dyspnea descriptors in asthma patients.

This cross-sectional community-based study was conducted on the general population of Arar city (Northern Border Province, Saudi Arabia) of both sexes, during the period from $1^{\text {st }}$ October, 2015 to $30^{\text {th }}$ June 2016 to evaluate the prevalence of dyspnea among a representative sample of Arar city. The results and outcomes of this study present unique information on trends in dyspneic patients, their sociodemographic characteristics, and relationships between them and other factors affecting them. In the present study, the total number of participants was 250 among which $183(73.2 \%)$ were males and $67(26.8 \%)$ were females. The participants were grouped in 4 groups according to age classification, most of which were in the 20-40 years old group, counting 169 (67.6\%). However, $50(20 \%)$ of the patients were 41-60 years old, $12(4.8 \%)$ were over 60 years old, and $19(7.6 \%)$ were less than 20 years old.

Dyspnea was reported in $35.2 \%$ of the study population. Dyspnea was found to be less prevalent in the study of Grønsethet $\boldsymbol{a l l}^{[18]}$, as $27 \%$ of the total population had reported dyspnea. Some populationbased studies have reported a dyspnea prevalence of more than $20 \%{ }^{[19,20]}$.

The causes of dyspnea reported in our study were mainly of unknown causes (38.6\%), bronchial asthma (23.9\%), allergy (22.7\%), psychological causes $(12.5 \%)$, cardiac causes $(1.1 \%)$, and COPD $(1.1 \%)$. In Grønsethet al. ${ }^{[18]}$ study, it was observed that dyspnea exhibited geographical variation beyond that which might be explained by known risk factors such as age, sex, education, smoking habits, comorbidities as obesity and life style.

Our study showed that dyspnea was more common among females as $44.8 \%$ of females reported dyspnea while it was reported in only $31.7 \%$ of males. Our 
study has also shown that dyspnea was most prevalent among the $<20$ age group by ratio as $52.6 \%$ of them reported dyspnea. However, $36.1 \%$ of subjects aged between 20 and 40 have reported dyspnea. Precipitating causes of dyspnea were found to be mostly due to dust (30.7\%), smoking (22.7\%), climate changes $(14.7 \%)$, nervousness (13.6\%), specific food/ingested material (11.4\%), and excess physical activities $(6.8 \%)$. It is also founded in our study that $56.5 \%$ of participants with family history of dyspnea suffered from dyspnea. While $72.9 \%$ of those who did not have a family history of dyspnea did not suffer any dyspnea.

In Grønsethet $a{ }^{\left[{ }^{[9]}\right.}$ study, it was observed that occurrence of unexplained dyspnea could be related to known risk factors related to age, sex, education, smoking habits, comorbidities as obesity and life style.

Another population-based studies have reported a high-prevalence of dyspnea, cardiopulmonary diseases, life-style, obesity and subclinical medical conditions might have explained this dyspnea ${ }^{[19,20]}$.

\section{CONCLUSION}

Dyspnea was reported in 35.2\% of Arar population. Our study showed that dyspnea was more common among females than males. large scale study with detailed investigations about causes and precipitating factors are required.

\section{ACKNOWLEDGMENT}

Authors woud like to thank Jazzaa Hammad M Alshammari, Wael sughayyir G alanazi, (Medical students, Northern Border University) and Amjad Ayed Allogmani (Medical students, Faculty Of Medicine Umm-Alqura University) who help in data collection and different steps of the research.

\section{REFERENCES}

1.Burney P, Jarvis D, Perez-Padilla R (2015): The global burden of chronic respiratory disease in adults. Int $\mathbf{J}$ Tuberc Lung Dis.,19(1):10-20.

2.Koul P, Patel D (5015): Indian guidelines for asthma: adherence is the key. Lung India,32(7):1-2

3. Charles J, Ng A, Britt $\mathrm{H}$ (2005): Presentations of shortness of breath in Australian general practice, AustFam Physician, 34 (7):520-531

4. Mulrow CD, Lucey CR, Farnett LE (1993): Discriminating causes of dyspnea through clinical examination, J Gen Intern Med. , 8 (7):383-392

5. Pratter MR, Curley FJ, Dubois J et al. (1989): Cause and evaluation of chronic dyspnea in a pulmonary disease clinic, Arch Intern Med., 149 (10):2277-2282.
6. Fletcher CM, Elmes PC, Fairbairn AS et al. (1959): The significance of respiratory symptoms and the diagnosis of chronic bronchitis in a working population, Br Med J., 2(5147): 257-266.

7. Jakeways N, McKeever T, Lewis SA et al. (2003): Relationship between FEV1 reduction and respiratory symptoms in the general population. EurRespir J.,21:658663.

8. Enright PL, Kronmal RA, Higgins MW et al. (1994): Prevalence and correlates of respiratory symptoms and disease in the elderly. Cardiovascular Health Study. Chest, 106:827-834.

9. Hardie JA, Vollmer WM, Buist AS et al. (2005): Respiratory symptoms and obstructive pulmonary disease in a population aged over 70 years. Respir Med., 99:186-195.

10. Parshall MB, Carle AC, Ice U et al.(2012): Validation of a three-factor measurement model of dyspnea in hospitalized adults with heart failure. Heart Lung, 41: 4456.

11.Desbiens N, Mueller-Rizner N, Connors A et al.(1997): The relationship of nausea and dyspnea to pain in seriously ill patients. Pain,71:149-56.

12.Hammond EC (1964): Some preliminary findings on physical complaints from a prospective study of 1,064,004 men and women. Am J Public Health Nations Health, 54:11-23.

13.Shih FJ, Chu SH (1999): Comparisons of AmericanChinese and Taiwanese patients' perceptions of dyspnea and helpful nursing actions during the intensive care unit transition from cardiac surgery. Heart Lung, 28: 41-54.

14.Berliner D, Schneider N, Welte T et al.(2016): The Differential Diagnosis of Dyspnea. Deutsches Ärzteblatt International, 113(49), 834-845.

15.World Health Organization (2016): The top 10 causes of death. Geneva: Available from. http://www.who.int/news-room/fact-sheets/detail/the-top10-causes-of-death3.

16.Mahler DA, Harver A, Lentine $\mathrm{T}$ et al. (1996):Descriptor of breathlessness in cardiorespiratory disease. Am J RespirCrit Care Med.,154:1357-63.

17.Sajadi S, Majidi A, Abdollahimajd F et al. (2017):Relationship between Dyspnea Descriptors and Underlying Causes of the Symptom; a Cross-sectional Study. Emergency, 5(1): e62.

18.Grønseth R, Vollmer W, Hardie J et al. (2017): Predictors of dyspnea prevalence: Results from the BOLD study. The European Respiratory Journal, 43(6): 1610 1620 .

19.Eagan TM, Bakke PS, Eide GE et al. (2002): Incidence of asthma and respiratory symptoms by sex, age and smoking in a community study. EurRespir J., 19:599-605.

20.Jakeways $\mathrm{N}$, McKeever $\mathrm{T}$, Lewis $\mathrm{SA}$ et al. (2002):Relationship between FEV1 reduction and respiratory symptoms in the general population. EurRespir J.,

21:658-663. 